\title{
1 Investigation of the temporal and spatial dynamics of muscular action potentials through
}

2 optically pumped magnetometers

3 Philip J. Brosera*, Justus Marquetand ${ }^{\mathrm{b}, \mathrm{d}}$, Thomas Middelmann ${ }^{\mathrm{c}}$, Davide Sometti ${ }^{\mathrm{d}}$, Christoph

4 Braun $^{\mathrm{d}, \mathrm{e}, \mathrm{f}}$

$5 \quad$ a Children's hospital of eastern Switzerland, Sankt Gallen, Switzerland

6 b Department of Epileptology, Hertie-Institute for Clinical Brain Research, University of

7 Tübingen, Tübingen, Germany

$8 \quad$ c Physikalisch technische Bundesanstalt, Berlin, Germany

9 d MEG Center, University of Tübingen, Germany

10 e Hertie-Institute for Clinical Brain Research, Tübingen, Germany

$11{ }^{\mathrm{f}} \mathrm{CIMeC}$, Center for Mind/Brain Sciences, Trento, Italy

12

$13 *$ Corresponding author

14 Dr. Philip J. Broser (ORCID iD: 0000-0003-4477-1432)

15 Philip.Broser@kispisg.ch

$16 \quad$ Philip.Broser@icloud.com

17 Ostschweizer Kinderspital,

18 Neuropediatric Department

19 Claudiusstrasse. 6

$20 \mathrm{CH}-9006$ St. Gallen

$21 \quad$ Tel. +41712431928

23 Word count (main text): 4481

24 Keywords: peripheral nerve system, muscle action potential, optically pumped magnetometer, magnetic field, finite wire model, magnetic moving dipole model, magnetomyography 


\section{ABSTRACT}

\section{Aim:}

This study aims to simultaneously record the magnetic and electric components of the propagating muscular action potential.

\section{Method:}

A single-subject study of the monosynaptic stretch reflex of the musculus rectus femoris was performed; the magnetic field generated by the muscular activity was recorded in all three spatial directions by five optically pumped magnetometers. In addition, the electric field was recorded by four invasive fine-wire needle electrodes. The magnetic and electric fields were compared, and modelling and simulations were performed to compare the magnetic field vectors with the underlying muscular anatomy of the rectus femoris muscle.

\section{Results:}

The magnetomyography (MMG) signal can reliably be recorded following the stimulation of the monosynaptic stretch reflex. The MMG signal shows several phases of activity inside the muscle, the first of which is the propagating muscular action potential. As predicted by the finite wire model, the magnetic field vectors of the propagating muscular action potential are generated by the current flowing longitudinal to the muscle fiber. Based on the magnetic field vectors, it was possible to reconstruct the pinnation angle in the muscle. The later magnetic components are linked to the activated contractile apparatus.

\section{Interpretation:}

MMG allows to analyze the muscle physiology from the propagating muscular action potential to the initiation of the contractile apparatus. At the same time this methods reveal information

52 about muscle fiber direction and extend. With the development of high-resolution magnetic 

precision. This method could be used in clinical medicine but also in sports and training science.

What this paper adds:

- A robust technique for triggering a muscular action potential that can be recorded by MMG and needle EMG simultaneously

- The correlation of the MMG signal with the needle EMG signal

- A method for detecting the direction of the propagating muscular action potential examined muscle

Abbreviations:

68

- MMG: magneto myography

69

- OPM: optically pumped magnetometer 


\section{Introduction}

The smooth and controlled movements of the skeletal muscles require the well-controlled activation of the contractile apparatus along the whole length of the contracting muscle (Ghezzi, 1991). Here, the precise initiation of the molecular muscular contractile apparatus critically depends on the timing and spread of the excitation along the muscular fiber by the muscular action potential (Martonosi, 2000). After activation of the postsynaptic neuromuscular endplate by the motoneuron, the signal to initiate the contractile apparatus spreads along the muscular fiber through the muscular action potential (Henneberg, 1997). The action potential not only spreads in the longitudinal direction but also along the T-tubuli in the radial direction. The depolarization of the T-tubuli membrane leads to an opening of the ryanodine receptors and thus initiates a calcium influx in the cytoplasm from outside the cell as well as from the sarcoplasmic reticulum. The increase in the calcium concentration finally activates the muscle contraction (Martonosi, 2000).

The muscular action potential generates a measurable electric and magnetic field, and both fields disclose valuable physiological information (Farina, 2001; Broser, 2020). The electric field is, for instance, used in motor nerve conduction studies to determine the exact time the muscle is activated by the electrically stimulated motor nerve. Given that the signal is generated by the summation of the electric field of many neuro muscular units (Broser, 2020), the signal is called the compound muscle action potential (CMAP). When examining the precise timing of the muscular action potential of a distinct set of neuro muscular units, needle EMG recording is currently the technique of choice (Moritani, 2004).

However, this technique is painful and only allows recording at one or a few locations in the muscle. However, only recently it has been shown that recording the magnetic field of the muscular action potential allows a precise non-invasive analysis of the temporal and spatial dynamics (Broser, 2020). Further, the magnetic field can theoretically be linked to the current 
flowing inside the muscle fiber and thus reveal the spread of excitation during the propagation of the action potential.

In the pioneering study by Broser (2020), the magnetic field generated by the muscular action

101 potential propagating along the muscle fibers of an intrinsic foot muscle was studied. In order

to obtain highly synchronized neuromuscular units, the supplying nerve was electrically stimulated. This study showed that the muscular action potential can be recorded with a high can be localized by recording the magnetic field vectors.

106 So far the golden standard for the study of the muscular action potential is invasive needle

107 myography. Optically pumped magnetometers are a promising alternative. How comparable needle EMG and OPM recording are needs to be evaluated. This is especially important when considering that the magnetic field reflects more the current than transmembrane voltage (as concentric needle EMG does).

111 Moreover, previous studies on MMG (Broser, 2018; Broser, 2020) relied on an artificial

112 stimulus by electrically stimulating the supplying nerve rather than using a physiological paradigm involving intentional muscle activations or eliciting a monosynaptic reflex response.

114 In addition, so far, only small intrinsic hand or foot muscles have been measured, with large 115 and anatomically more complex muscles remaining to be studied. Therefore, we developed an 116 experimental protocol and designed an experimental setup to record the magnetic components

117 of the propagating muscle action potential (magnetomyogram, MMG) and, simultaneously, the monopolar fine-wire electromyogram (EMG) after monosynaptic reflex stimulation.

119 With this study we aimed to explore the full potential of the MMG technique. Especially to 120 investigate if its possible to analyze both, the physiology of the muscular action potential and 121 also the fiber structure of the muscle under investigation. 
123 For our analysis, we therefore selected the rectus femoris muscle. The rectus femoris is a

124 longitudinal fusiform muscle (Ward, 2008) that partially flexes the hip and extends the leg at

125 the knee (see Figure 1A). The muscle starts at two locations: the anterior inferior iliac spine and

126 the upper rim of the acetabulum. The distal tendon of the muscle is part of the M. quadriceps

127 tendon, which becomes the patella ligament and which is connected to the tuberositas tibiae.

128 The superficial fibers are arranged in a three-dimensional bipenniform manner (Ward, 2009;

129 Blemker, 2006). This complex anatomical situation is outlined in Figure 1B and Figure 2 Panel

130 A. The proximal fibers are angulated with an angle to the longitudinal axis of the muscle of

131 about $14 \pm 4$ degrees (see Figure 2A). The distal fibers run roughly parallel to the longitudinal

132 axis. In addition to the angulation in the coronal plane, the fibers are also angulated in the

133 sagittal plane (see Figure 2 Panel B).

134 In this study we combined the OPM measurement of the magnetic field with fine-wire needle

135 EMG electrodes (MedCat $0.4 \times 10 \mathrm{~mm}$ Platin-Iridium needle) in order to measure the electric

136 field at the same time. The muscle was activated by triggering the monosynaptic patellar tendon

137 stretch reflex (Gürbüz, 2015) using a custom-made paramagnetic tendon hammer.

\section{METHOD}

\subsection{Principal setup}

A single-subject, experimental study was conducted at the MEG-Center of the

142 University of Tübingen, Germany in October 2020. Experiments were performed according to

143 the standards by the World Medical Association (World Medical Association, 2001). The

144 subject of this study was an author of this publication, and he gave his consent for his data to

145 published. The experiment was designed specifically to record the magnetic activity of the left

146 rectus femoris muscle (Figure 1 Panel A) after triggering the monosynaptic patellar tendon

147 stretch reflex (Figure 2 Panel B). Prior to the experiment, the muscle was imaged via high 
148 resolution muscle ultrasound (see Figure 1 Panel C) in order to determine the longitudinal axis

149 of the muscle. To estimate the direction of the muscular fibers, a model based on the ideas in

150 Blemker (2005) was developed and fitted to the subject's body size using muscular ultrasound

151 images. The electric activity of the muscle was recorded by four monopolar EMG needle

152 electrodes (MedCat 0.4 x 10 mm Platin-Iridium needles), and the magnetic field was measured

153 by five OPM sensors (Figure 1 Panel A and Panel C).

First, muscular ultrasound imaging (Mindray TE7, 14Mhz-linear probe, see Figure 1D)

was used to measure the size and longitudinal length of the left rectus femoris muscle. The parameters of the muscular fiber model were adapted accordingly (see Figure 1B). After

157 ultrasound imaging, the subject sat down on a comfortable chair inside a magnetic shielded

158 room (Ak3b, VAC Vacuumschmelze, Hanau, Germany). The left leg of the subject was supported by a pillow (Figure $2 \mathrm{C}$ ) so that the rectus femoris was completely relaxed and the patella tendon could be easily reached by an examinator using a tendon hammer (Figure $2 \mathrm{C}$ ).

The hammer was equipped with fiber optics in order to produce a trigger signal at the time point

162 the hammer made contact with the participant's skin. To produce the trigger, one of the two

163 fibers built into the hammer provided an amplitude modulated light beam, and the other measured the reflection of the beam (Keyence Digital Fiber Sensor FS-N10). Approaching the participant's skin with the hammer caused an increase in the reflected intensity until the skin was touched. At that instant, the reflected intensity dropped sharply. were placed inside or near the rectus femoris muscle (Figure 1B and C).

170 If possible, the needle electrodes were placed in a distal to proximal order along a line parallel 171 to the fiber direction estimated via ultrasound imaging (see Figure 1A and B). In addition, a

\footnotetext{
${ }^{1}$ Bipolar EMG needles are ferromagnetic and therefore cannot be used with OPM devices.
} 
172 surface reference electrode was placed on the lateral skin at the level of the left knee, and a

173 ground electrode was placed on the skin of the right shoulder.

174 Five optically pumped magnetometers (four OPM [No. 1 to 4], QZFM-gen-1.5 and one OPM

175 [No. 5], Generation QZFM-gen-2) (QuSpin Inc., Louisville, CO, USA) were placed in a distal

176 to proximal order along a line (see Figure 1A and B) parallel to the longitudinal extend of the

177 muscle. The magnetometers were placed about 2-3 $\mathrm{mm}$ above the skin surface and were based

178 on an optically detected zero-field resonance in hot rubidium vapor, which was contained in a

179 vapor cell measuring $3 \times 3 \times 3 \mathrm{~mm}^{3}$. The center of the cell had a distance of $6.2 \mathrm{~mm}$ to the

180 exterior of the housing (6.5 $\mathrm{mm}$ in the case of OPM No. 5), which measured (Generation 1.0)

$18113 \times 19 \times 85 \mathrm{~mm}^{3}\left(12.4 \times 16.6 \times 24.4 \mathrm{~mm}^{3}\right.$ in the case of OPM No. 5). The small size of the

182 OPM sensors allows for easy handling and their flexible adaptation to specific geometrical 183 situations (Boto et al., 2017, Osborne et al., 2018, Sander et al. 2020). OPMs are capable of

184 measuring two components of the magnetic field vector: the $y$ - and z-direction. They measure

185 with a magnetic field sensitivity in the order of $15 \mathrm{fT} / \sqrt{\mathrm{Hz}}$ in a bandwidth of $3-135 \mathrm{~Hz}$ and a

186 dynamic range of a few nanoteslas. To adapt to a non-zero magnetic background field, the

187 sensors are equipped with internal compensation coils that can cancel magnetic background

188 fields of up to $200 \mathrm{nT}$ in the sensing vapor cell.

189 Our set of OPM sensors could simultaneously record the magnetic field in two orthogonal

190 directions ( $\mathrm{y}$ and $\mathrm{z}$ ). In order to also record the $\mathrm{x}$-direction, we repeated the measurements with

191 the sensors turned by 90 degrees around the z-direction.

\section{$192 \quad 2.2$ Stimulation}

193 In order to record temporal synchronized muscular action potentials, the muscle was indirectly

194 stimulated by eliciting the monosynaptic patellar stretch reflex (Gürbüz, 2015). To this end, a 195 custom-made non-magnetic tendon hammer made of plastic was used (Figure 2C). The head of 196 the hammer hosted two optical fibers. When the hammer was in close proximity to the skin, the 
197 light emitted from one of the fibers would be reflected by the skin back into the other fiber.

198 Both fibers were tunneled out of the of the magnetic shielded room and connected to a light-

199 emitting diode and a photo transistor. The voltage of the photo detector was amplified and fed

200 into one analog-digital-converter (ADC) channel of the MEG recording system. Just a few

201 millimeters before the hammer hit the skin, the amount of reflected light peaks — and, thus, the

specific time points of the stimulation - could be determined (see Figure 2D). Several series of stimulations were recorded. First, a series was measured without boosting the reflex. Then, the

perform the Jendrassik maneuver. To grossly estimate the muscular anatomy during the

contraction, a motion-mode (M-mode) ultrasound examination was done after the experiment.

207 The M mode image was registered to the OPM and EMG data (see Figure 2D ).

\subsection{Recording}

210 The data was recorded with the data acquisition function of the MEG system (CTF Omega 275,

211 Coquitlam, BC, Canada) installed in the magnetically shielded rom. The analogue signals

212 (OPMs, EMG, and Hammer) were digitized with a sampling rate of 2343.8 samples per second.

213 A low-pass filter of $100 \mathrm{~Hz}$ was applied to the analogue signal of the OPMs. Four of the EEG

214 channels included in the CFT MEG system were used to record the signals from the fine-wire needle EMGs. The EMG signals were band-pass filtered with a Butterworth filter with an edge

216 frequency set at $5 \mathrm{~Hz}$ (high pass) and $800 \mathrm{~Hz}$ (low pass). The OPM system has an intrinsic

217 delay between the measurement and analogue output; this delay was measured to be $3 \mathrm{~ms}$. The

218 data was post-hoc calibrated so that the magnetic field, electric potential, and signal of the hammer were in temporal synchrony. 


\subsection{Data processing and simulations}

222 As described above, the data was recorded with the CTF System. The data was exported as

processing. The signal from the hammer was used to separate the data into distinct trials (see

Figure 2 D). In order to compare different trials with each other, the trial data was calibrated using the peak of the monopolar signal from EMG 1 as a reference $(t=0 \mathrm{~ms}$, see Figure $2 \mathrm{D})$. Apart from the offset calibration, no further processing was applied.

\subsection{Modelling of the propagating muscular action potential}

In addition to its temporal characteristics, the magnetic signal contains valuable geometric information. In order to link the obtained time-dependent magnetic fields with the underlying structural physiology, the finite wire model described in Broser (2020) was here applied, and parameter fitting was performed. The calculation was performed using Maple ${ }^{\mathrm{TM}}$ (Waterloo, potential propagates linearly along the muscle fiber. Therefore, the position of the action 236 potential is parametrized by:

$\vec{L}(s)=\left(\begin{array}{c}x_{0}+s * \sin (\vartheta) * \cos (\varphi) \\ y_{0}+s * \sin (\vartheta) * \sin (\varphi) \\ z_{0}+s * \cos (\vartheta)\end{array}\right)$, with $\frac{d \vec{L}}{d s}=\left(\begin{array}{c}\sin (\vartheta) * \cos (\varphi) \\ \sin (\vartheta) * \sin (\varphi) \\ \cos (\vartheta)\end{array}\right)$,

with L denoting the position of the muscular AP in space, s parameterizing the longitudinal extend, and the theta and phi angles defining the orientation of the fiber direction in polar coordinates. The model assumes - without loss of generality - that the recording sensor is

243 located at position $(0,0,0)$, with its z-direction pointing downwards.

244 The membrane potential orthogonal and longitudinal to the fiber orientation is modelled 


$$
V(s)_{\text {membrane }}=\left(\begin{array}{c}
a * s^{3} e^{-s}+b ; s>0 \\
0 ; s \leq 0
\end{array}\right)
$$

249 with $a=96 \frac{\mathrm{mV}}{\mathrm{mm}^{3}}$ and $b=-90 \mathrm{mV}$. The magnetic field then calculates to

$$
\vec{B}(s)=\frac{\mu_{0}}{4 \pi} \int_{s}^{s-\Delta \mathrm{s}} I(s-t) * \frac{\vec{R}(t) \times \frac{\overrightarrow{d L}}{d s}}{|R|^{3}} d t \text { with }
$$

$$
I(t)=\frac{A_{\text {fibre }}}{r_{i x}} *\left(\frac{d V_{\text {membrane }}}{d s}\right)(t), R(s)=\left(\begin{array}{l}
0 \\
0 \\
0
\end{array}\right)_{\text {PositionOPM }}-L(s)
$$

with $r_{i x}=173 \Omega * c m=17.3 \Omega * m m$ (Henneberg and Roberge, 1997), $\Delta s=15 \mathrm{~mm}$.

256 A detailed description of the model can be found in Broser (2020).

\section{Results}

260 The subject had an upper-leg length of $30 \mathrm{~cm}$ (patella to groin). The upper aponeurosis of the M. rectus femoris muscle was $8 \mathrm{~mm}$ below the skin (see Figure 2D). After hitting the patellar

262 tendon with the reflex hammer, a contraction of the rectus femoris muscle could be reliably

263 triggered. Figure 2D shows the recorded signal of the hammer, EMG electrode 1, and the magneto-myogram (MMG) signal recorded with OPM 1 for the $z$ - and y-direction in a time window of $400 \mathrm{~ms}$ around the time of the stimulation. In order to support the clarity of the

266 manuscript, throughout the publication, the time window of the plots has been defined so that 267 the highest negative peak in EMG electrode 1 for each trial defines the time point $0 \mathrm{~ms}$. About $26820 \mathrm{~ms}$ after the peak of the hammer signal, a small positive deflection followed by a large 
negative deflection can be detected in EMG channel 1. Simultaneously, a biphasic signal is recorded from OPM device No. 1 in the z- and y-direction. The biphasic signal is followed by

271 a short phase of electric and magnetic silence lasting about $10 \mathrm{~ms}$. Then, a large magnetic

272 component in the y-direction and later in the z-direction can be distinguished. Table I lists the

273 different time intervals that can be distinguished in the signals:

\begin{tabular}{|c|c|c|c|c|}
\hline Name & Time & $\begin{array}{c}\text { Electric (EMG I } \\
\text { monopolar) }\end{array}$ & $\begin{array}{c}\text { Magnetic (OPM } 1 \text { Z } \\
\text { and Y direction) }\end{array}$ & Description \\
\hline $\mathbf{I}$ & $-20 \mathrm{~ms}$ to $-5 \mathrm{~ms}$ & Silence & Silence & $\begin{array}{l}\text { Latency period between } \\
\text { stimulus and muscle } \\
\text { response }\end{array}$ \\
\hline II & $-5 \mathrm{~ms}$ to $5 \mathrm{~ms}$ & $\begin{array}{l}\text { Small positive, then } \\
\text { large negative, and } \\
\text { finally medium positive } \\
\text { deflection }\end{array}$ & $\begin{array}{l}\text { First field component in } \\
\text { positive y- and z- } \\
\text { direction; then small dip } \\
\text { followed by a second } \\
\text { smaller peak; and then } \\
\text { flipping of the direction } \\
\text { of both (y and z) field } \\
\text { components }\end{array}$ & $\begin{array}{l}\text { Propagating muscular } \\
\text { action potential }\end{array}$ \\
\hline III & $5 \mathrm{~ms}$ to $15 \mathrm{~ms}$ & Silence & Silence & Pre-activation period \\
\hline IV & $15 \mathrm{~ms} 80 \mathrm{~ms}$ & Silence & $\begin{array}{l}\text { Strong signal in the } \\
\text { negative } \mathrm{Y} \text { direction }\end{array}$ & $\begin{array}{l}\text { (unknown presumably } \\
\text { first interaction myosin- } \\
\text { actin structures) }\end{array}$ \\
\hline $\mathbf{V}$ & $80 \mathrm{~ms}$ to $300 \mathrm{~ms}$ & Silence & $\begin{array}{l}\text { Magnetic activity in the } \\
y \text { - and z-direction }\end{array}$ & Muscle contraction \\
\hline
\end{tabular}

Table I: Time intervals of the MMG Signal

275 In order to obtain an approximation of when the contraction of the muscle starts, M-mode ultrasound scans have been performed before the OPM measurement. At the bottom of Figure 2D, an M-mode image is shown. This data suggests that the interval V corresponds to the muscle contraction. The source of the magnetic field during interval IV remains unknown. 


\subsection{Reproducibility and signal-to-noise ratio}

282 In order to test the reproducibility of the MMG signals, 12 trials were referenced for the peak

283 of the maximum positive signal in EMG 1 and are plotted together in Figure 3 for OPM 1 and

2842 in the $y$ - and z-direction and $x$ - and z-direction (see Figure 3).

286 The signal amplitude of the background MMG signal was determined by measuring the difference of the maximum and minimum signal in the time period from -50 to $-20 \mathrm{~ms}$ prior to the peak in EMG 1. The signal amplitude of the background was defined as the absolute difference between the minimum and maximum value. The foreground signal amplitude of the

MMG signal was measured as the highest positive signal in the time period from $-5 \mathrm{~ms}$ to $5 \mathrm{~ms}$.

The signal-to-noise ratio was calculated by dividing the foreground amplitude by the background amplitude.

Table 1 shows the signal-to-noise ratio of the MMG signal in the different directions and OPM sensor positions. For all sensors, the signal-to-noise ratio is above 3, and the magnetic field in the y-direction has the highest signal-to-noise ratio out of all sensors. The main variability in the ratio values is due to the varying intensity of the background signals. Specifically, the background signal is lowest in the y-direction (see Figure 3) and highest in the x-direction.

Table 1. Signal-to-noise ratio. (Median [Max-Min], $n=12$ )

\begin{tabular}{|c|c|c|c|}
\hline OPM Nr. & X-direction & Y-direction & Z-direction \\
\hline 1 & $8.07(16.78-2.16)$ & $9.78(13.62-3.85)$ & $3.32(4.66-1.54)$ \\
\hline 2 & $3.95(5.86-2.12)$ & $9.40(31.19-3.37)$ & $3.15(4.65-1.89)$ \\
\hline
\end{tabular}

301 Given that the sensors had to be turned around the longitudinal axis in order to record the $\mathrm{x}$

302 direction, it was necessary to test if the sensors picked up the same signal prior to and after

303 rotation. To compare the signal profiles, Figure 3 shows in Panels A and B (right side) the z- 
direction prior to the rotation and in Panel C and D (right side) the signal in the z-direction after axial rotation. If one compares Panel $\mathrm{A}$ and $\mathrm{C}$ with $\mathrm{B}$ and $\mathrm{D}$, one can recognize that the signal during the period of the muscular action potential is the same before and after the rotation of the sensors. However, the later components show more variability and were therefore not 308 further analyzed in this study.

309 Given the high reproducibility of the signal of the propagating muscular action potential and the excellent signal-to-noise ratio with values above three, further analysis was performed on individual trials without any averaging.

\subsection{Correlation of MMG signal and EMG signal}

314 In order to analyze the temporal characteristics of the EMG and MMG signals, the signals are

315 plotted in Figure 4 with focus on the time period of -50 to $50 \mathrm{~ms}$ - the time period of the propagating muscular action potential—-for each OPM sensor and all three directions $(\mathrm{x}, \mathrm{y}, \mathrm{z})$.

In addition to the OPM signal, each plot depicts the calculated bipolar EMG signal of the neighboring fine-wire EMG electrodes (i.e., d[EMG1, EMG2] for the bipolar EMG signal,

319 which was calculated by $\mathrm{V}_{\mathrm{EMG} 1}-\mathrm{V}_{\mathrm{EMG} 2}$ ). Both signals - the bipolar EMG signal and the MMG

320 signal — have the same temporal onset and same duration. The MMG signals are strongest in 321 the $\mathrm{y}$ direction, while the activity in the $\mathrm{z}$ direction is again larger than the activity in the $\mathrm{x}$ 322 direction. Taking the finite wire model described in Broser (2020) into consideration, this 323 suggests that the principal propagation direction of the muscular action potentials is in the $\mathrm{x}$ 324 direction. When taking the simplified relationship between the scalar magnetic field strength $325 \mathrm{~B}$, the current $\mathrm{I}$, the length of the wire (extend of the muscular action potential) s, and the distance between the sensor and current source (Westgard, 1997):

$$
B \sim \frac{I * S}{r^{2}}
$$




$$
I \sim\left(V_{E M G 1}-V_{E M G 2}\right)
$$

330 (with $V_{E M G 1}$, the voltage, measured at EMG Position 1), one can obtain the simplified 331 relationship:

$$
B \sim\left(V_{E M G 1}-V_{E M G 2}\right) .
$$

333 This linear relationship is identifiable in most of the MMG and EMG traces (see supplementary

334 Figure 2). Given that the bipolar fine-wire EMG closely correlates with the current flowing in

335 the tissue between the two electrodes as well as the fact that the magnetic field is generated by

336 the current and not by the transmembrane membrane voltage, this finding is expected. Even so,

337 this finding emphasizes the important fact that the MMG signal correlates with the electric

338 current flowing in the muscle (in contrast, all other electrophysiology techniques measure the

339 transmembrane voltage).

340 To further analyze the OPM signal profile, it is important to consider the precise anatomical

341 structure of the muscle at the measurement position. The orientation of the muscular fiber,

342 which determines the direction of the propagation of the muscular action potential, especially

343 needs to be considered. Therefore, Figure 4 (right side) shows a model of the rectus femoris

344 muscle, highlighting the fiber direction in the xy plane as well as the position of the selected

345 OPM sensors and the neighboring fine-wire EMG positions.

\section{$346 \quad 3.3$ Modelling the OPM Signal}

347 Based on the magnetic field vector components, the direction of the propagating muscle action

348 potential can be estimated. Due to the indirect stimulation by triggering a reflex response, the

349 neuro muscular units are only partly in temporal synchrony. Therefore, both the EMG and the

350 MMG signals are generated by muscular action potentials in different temporal phases.

351 However, at the time of the signal onset, only one unit is activated, and, therefore, the direction

352 can be estimated by the first deflection from the baseline. In order to do so, a parameter fitting

353 approach as described in Broser (2020) and outlined in the method section was conducted. 
354 Figure 5 shows the estimated directions of the propagating muscular action potential at the different positions of the muscle. As expected, the direction vector turns from position OPM 4-about 20 degrees angulated - to facing almost straight forward for position OPM 1. Interestingly, for the position of OPM 5, we found a propagation direction parallel to the longitudinal extend of the muscle when we expected an angulation of about 20 degrees. In addition, the estimation of the direction for position OPM 3 is difficult given that the fist deflection in the z-direction is very small.

\section{Discussion}

In this study, we used optically pumped magnetometers to record the magnetic field components of the propagating muscular action potential along the fibers of the rectus femoris muscle. The muscle was activated by triggering a monosynaptic reflex response. About $20 \mathrm{~ms}$ after the hammer touched the skin of the subject, we could record a signal from the OPM potential, a latency period of about 10 ms follows. Then, a strong magnetic signal of unknown origin present in all three spatial directions can be recorded. We assume that this signal is due to the activity in the contractile apparatus or generated by movement. However, this remains to 372 be clarified.

To test whether the stimulation of triggering a reflex results in a stable and reproducible

374 response, we time-locked the MMG data to the peak of the EMG 1 electrode, plotted the data, 375 and measured the signal-to-noise ratio, finding that this type of stimulation leads to a stable response with a high signal-to-noise ratio. To further analyze the muscular action potential, the analysis focused on the time period of $-50 \mathrm{~ms}$ to $50 \mathrm{~ms}$ - around the peak of EMG 1. First, it 
exists. Previously, it was theoretically shown (Broser, 2020) that the MMG signal is generated by the current flow inside the muscular fiber. To obtain a gross estimate of the current flowing inside the rectus femoris muscle, we calculated the bipolar fine-wire EMG between the individual OPMs. Especially for OPMs 1 and 2, where the fibers are almost parallel to the longitudinal extend, the signal amplitude and curvature are in good correspondence. This result

384 demonstrates that the magnetic field is, as theoretically expected, a result of the current flowing in the muscle, which is a completely new perspective of muscular physiology when compared to the techniques available so far, i.e., needle EMG measures the transmembrane voltage

387 (Moritani, 2004).

The stimulation of the muscle by triggering a monosynaptic reflex response only leads to a weakly synchronized activity in the muscle. The neuro muscular units fire at slightly different timepoints. Therefore, the signal from muscle fibers with different time phases are recorded, making precise modelling difficult. However, at the very onset of the signals, modelling is possible; so, the direction of the muscular action potential can be estimated. Using this approach, we could reproduce the different pinnation angles inside the rectus femoris muscle given in the literature (Blemker, 2006). This finding demonstrates nicely how MMG can be used to analyze the direction of the muscle fibers.

While it was quite successful, this study had some important limitations. The OPM devices used have a restricted bandwidth, and, therefore, fine and fast components of the muscular 398 action potential could not be recorded. In addition, the sensors used could only record the 399 magnetic field in two directions, and, thus, to measure the signal in the third dimension, the 400 sensors had to be manually turned during the experiment. Moreover, the anatomy of the rectus 401 femoris is complex and changes significantly in short spatial intervals; therefore, a high-density 402 grid of OPM sensors would be necessary to map the MMG precisely.

403 In conclusion, recording the magnetic field of the muscle not only allows for obtaining a non404 invasive alternative for needle EMG recordings but also delivers information thus far 
inaccessible. First, the sensors record the current inside the muscle instead of the transmembrane voltage, and they can therefore reflect the spreading of excitation more precisely. Second, the vectorial character of the magnetic field discloses the direction of the current flow and therefore allows for drawing conclusions about the geometry of the fiber structure.

410 In addition to the magnetic components of the muscular action potential, we found additional 411 magnetic field components about $20 \mathrm{~ms}$ after the action potential - the time we also see 412 movement in the $\mathrm{M}$ mode ultrasound images - which we think originate from the contractile 413 apparatus or from movement inside the muscle. If this is confirmed by further experiments, it 414 could open up a whole new perspective of muscle physiology. For instance, this information 415 would make it possible to link the propagating action potential with the activity of the contractile apparatus. From classical experiments, it is known that changes in the delay of the 417 muscular action potential and the initiation of the interaction between myosin and action is 418 closely correlated to the training level of the muscle (El-Ashker, 2019).

419 In summary we could show in this study that the magnetic field correlates with the current 420 flowing in the longitudinal direction of the muscle fiber. The method is capable of showing the 421 fiber direction in the muscle and possible allows the measurement of the electro mechanical 422 delay.

423 So, MMG could open a new analysis method for the contractile apparatus in athletes as well as 424 in patients suffering from neuromuscular diseases. A first prove of a principal study (currently 425 in preparation) shows that pathological spontaneous muscular activity can be recorded by 426 MMG (Marquetand et al., in preparation).

427 In order to extend our knowledge regarding the sources of late magnetic field components 428 and to optimize the modelling of the muscular action potential, we plan to conduct a series of 429 animal experiments on isolated muscle fibers. These experiments will help to specifically 
bioRxiv preprint doi: https://doi.org/10.1101/2021.02.24.432771; this version posted February 25, 2021. The copyright holder for this preprint (which was not certified by peer review) is the author/funder, who has granted bioRxiv a license to display the preprint in perpetuity. It is made available under aCC-BY-NC-ND 4.0 International license.

430 understand the late magnetic field, which we currently assume to be generated by the contractile

431 apparatus.

432

\section{Acknowledgement}

434 We want to thank Jürgen Dax for the construction of the non-magnetic reflex hammer and the

435 support during the measurements.

436

437 


\section{References}

439 Alem O, Sander TH, Mhaskar R, LeBlanc J, Eswaran H, Steinhoff U, Okada Y, Kitching J, Trahms L, Knappe S. Fetal magnetocardiography measurements with an array of microfabricated optically pumped magnetometers. Phys. Med. Biol. 2015;60:4797.

442 Blemker SS, Delp SL. Rectus femoris and vastus intermedius fiber excursions predicted by three-dimensional muscle models. J Biomech. 2006;39(8):1383-91. doi: 10.1016/j.jbiomech.2005.04.012. Epub 2005 Jun 21. PMID: 15972213.

Boto E, Meyer SS, Shah V, et al. A new generation of magnetoencephalography: room temperature measurements using optically-pumped magnetometers. Neuroimage 2017;149:404-14. https://doi.org/10.1016/j.neuroimage.2017.01.034

Broser PJ, Knappe S, Kajal DS, et al. Optically pumped magnetometers for magnetomyography to study the innervation of the hand. IEEE Trans. Neural. Syst. Rehabil. Eng. 2018;26(11):2226-30. https://doi.org/10.1109/TNSRE.2018.2871947

Broser PJ, Middelmann T, Sometti D, Braun C. Optically pumped magnetometers disclose magnetic field components of the muscular action potential. J Electromyogr Kinesiol. 2020 Nov 23;56:102490. doi: 10.1016/j.jelekin.2020.102490. Epub ahead of print. PMID: 33259993.

Broser PJ, Luetschg J. Elektroneurograsche und elektromyographische Diagnostik in der Neuropaediatrie [Electromyography and electro-neurography in the neuropediatric 
El-Ashker S, Chaabene H, Prieske O, Abdelkafy A, Ahmed MA, Muaidi QI, Granacher U.

464

465

466

467

468

469

470

471

472

473

474

475

476

477

478

479

480

481

482

483

484

485

486

487

488 Effects of Neuromuscular Fatigue on Eccentric Strength and Electromechanical Delay of the Knee Flexors: The Role of Training Status. Front Physiol. 2019 Jun 26;10:782. doi: 10.3389/fphys.2019.00782. PMID: 31293448; PMCID: PMC6606703

Farina D, Merletti R. A novel approach for precise simulation of the EMG signal detected by surface electrodes. IEEE Trans. Biomed. Eng. 2001;48(6):637-46. https://doi.org/10.1109/10.923782

Farina D, Merletti R. Estimation of average muscle fiber conduction velocity from twodimensional surface EMG recordings. J. Neurosci. Methods 2004;134(2):199-208. https://doi.org/10.1016/j.jneumeth.2003.12.002

Ghezzi A, Callea L, Zaffaroni M, Zibetti A, Montanini R. Study of central and peripheral motor conduction in normal subjects. Acta Neurol. Scandmavica 1991;84(6), 503-6.

Gürbüz M, Bilgin S, Albayrak Y, Kızllay F, Uysal H. Biceps femoris late latency responses and the "notching sign" in spasticity. J Neuroeng Rehabil. 2015 Oct 20;12:93. doi: 10.1186/s12984-015-0084-7. PMID: 26482429; PMCID: PMC4612418.

Henneberg KA, Roberge FA. Simulation of propagation in a bundle of skeletal muscle fibers: modulation effects of passive fibers. Ann. Biomed. Eng. 1997;25(1):29-45. https://doi.org/10.1007/BF02738536

Murakami K, Fujisawa H, Onobe J, Sato Y. Relationship between Muscle Fiber Conduction Velocity and the Force-time Curve during Muscle Twitches. J Phys Ther Sci. 2014 Apr;26(4):621-4. doi: 10.1589/jpts.26.621. Epub 2014 Apr 23. PMID: 24764647; PMCID: PMC3996435.

Labyt E, Corsi M, Fourcault W, Laloy AP, Bertrand F, Lenouvel F, Cauffet G, Prado ML, Berger F, Morales S. Magnetoencephalography with optically pumped $4 \mathrm{He}$ magnetometers at ambient temperature. IEEE T. Med. Imaging 2019;38:90. 
Martonosi A. Animal electricity, $\mathrm{Ca} 2+$ and muscle contraction: a brief history of muscle research. Acta Biochim. Pol. 2000;47(3):493-516.

Marquetand J, Middelmann T, Dax J , Baek S, Sometti S, Grimm A, Lerche H, Martin P, Kronlage C, Siegel M, Braun C, Broser P. Optically pumped magnetometers reveal pathologic spontaneous activity non-invasively. Neurology, in preparation.

Mhaskar R, Knappe S, Kitching J. A low-power, high-sensitivity micromachined optical magnetometer. Appl. Phys. Lett. 2012;101:241105.

Moritani T, Stegeman D, Merletti R. Basic physiology and biophysics of EMG signal generation. In: Merletti R, Parker P, editors. Electromyography: physiology, engineering, and noninvasive applications. Wiley-IEEE Press 2004:1-25.

Osborne J, Orton J, Alem O, Shah V. Fully integrated, standalone zero field optically pumped magnetometer for biomagnetism. Proc. SPIE 10548, Steep Dispersion Engineering and https://doi.org/10.1117/12.2299197

Reincke M. Magnetomyographie mit dem SQUID [Magnetomyography with the SQUID]. Biomed. Eng. 1993;38(11):276-81.

Rosenfalck P. Intra- and extracellular potential fields of active nerve and muscle fibres: a physico-mathematical analysis of different models. Acta Physiol. Scand. Suppl. 1969;321:1-168.

509 Sander T, Jodko-Władzińska A, Hartwig, S, Brühl R, Middelmann T. Optically pumped magnetometers enable a new level of biomagnetic measurements. Advanced Optical Technologies, De Gruyter. 2020;9:247-251

512 Ward SR, Eng CM, Smallwood LH, Lieber RL. Are current measurements of lower extremity muscle architecture accurate? Clin Orthop Relat Res. 2009 Apr;467(4):1074-82. doi: 

PMC2650051.

516 Westgard J. Electrodynamic: a concise introduction. New York: Springer, 1997.

517 Wikswo JP, Barach JP, Freeman JA. Magnetic field of a nerve impulse: first measurements. Science 1980;208(4439):53-5. https://doi.org/10.1126/science.7361105

519 World Medical Association. Declaration of Helsinki: ethical principles for medical research involving human subjects. Bull. World Health Organ. 2001;79(4):373-4.

Zuo S, Heidari H, Farina D, Nazarpour K. Miniaturized magnetic sensors for implantable

\section{Figure Legends}

\section{Figure 1}

532 This figure shows the setup of the experiment and the relevant anatomical details.

534 A: Macroscopic anatomy of the rectus femoris muscle. The black squares with orange numbers show the positions of the OPM sensor in relation to the muscle. The black circles with blue numbers show the positions of the fine-wire EMG needles. 
B: The rectus femoris muscle has a three-dimensional bipenniform structure. This structure is shown in this model, which will be used throughout the manuscript.

C: Real-world image of the experiment setup.

543 D: US sonographic images of the muscle at the depicted locations.

\section{Figure 2}

A, B: Modell of the rectus femoris. The model highlights the three-dimensional bipenniform structure of the muscle. The proximal fibers are angulated about $20^{\circ}$ to the longitudinal extend; the distal fibers run almost parallel.

C: Image showing the left leg of the subject resting on a pillow. In addition, the paramagnetic tendon hammer is shown in the picture hitting the patella tendon.

D: Plot showing the signal traces of EMG 1 (blue), Hammer (green) and OPM 1 in the y-and $\mathrm{z}$-direction. The identified distinct time intervals are shown at the bottom of the $\mathrm{x}$ axis labeled with roman numbers. At the bottom of the image, an M mode ultrasound image,

\section{Figure 3}

562 The reproducibility of the OPM signal was tested by time referencing 12 trials and plotting 

horizontal lines at -50 to $-20 \mathrm{~ms}$ show the period during which the background signal was estimated. The small horizontal lines at the time of the peak show the time period during which the signal amplitude was estimated. The trial used for later analysis is shown colored.

Remark: The z-direction is shown with an inverted signal to optimize visibility.

Figure 4

For each OPM sensor (1-5) the signal in the z-, y-, and z-direction in the time period of -50 ms to $50 \mathrm{~ms}$ around the muscular action potential is shown. In addition, the location of the sensor in relation to the muscle anatomy is depicted on the right side of the figure.

Figure 5

578 For each sensor, the signal onset in the $\mathrm{x}-, \mathrm{y}-$, and $\mathrm{z}$-direction was used to model the magnetic field according to the finite wire model by Broser (2020). The resulting plots are shown in the middle; in addition, the direction of the simulated muscular action potential is shown on the right.

\section{Supplementary Figure 1}

587 This figure shows the monopolar EMG signal for each fine-wire electrode on the left and the bipolar EMG signal on the right. 
592 Supplementary Figure 2

593 OPM sensor 2 is between EMG 1 and 2. Assuming that the current flows in a straight line along the $\mathrm{X}$ axis, the magnetic field strength should show a linear correlation with the bipolar EMG signal (only the magnitude of the EMG signal is shown). 
bioRxiv preprint doi: https://doi.org/10.1101/2021.02 24.432771; this version posted February 25, 2021. The copyright holder for this preprint (which was not certified by peer review) is the author/funder, who has granted bioRxiv a license to display the preprint in perpetuity. It is made available under aCC-BY-NC-ND 4.0 International license.

\section{Figure 01}

A

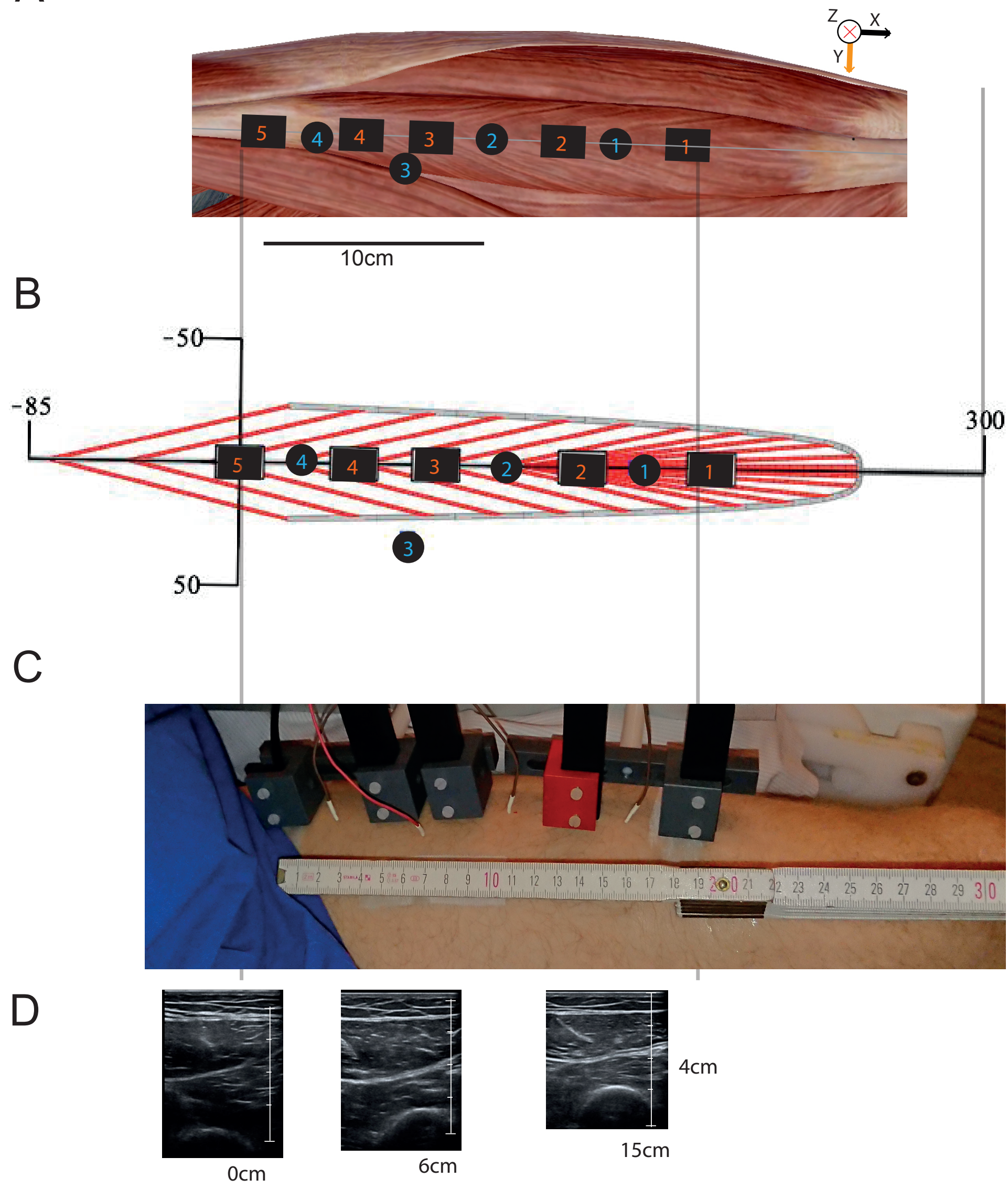


bioRxiv preprint doi: https://doi.org/10.1101/2021.02.24.432771; this version posted February 25, 2021. The copyright holder for this

preprint (which was not certified by peer review) is the author/funder, who has granted bioRxiv a license to display the preprint in perpetuity. It is made available under aCC-BY-NC-ND 4.0 International license.

\section{Figure 02}
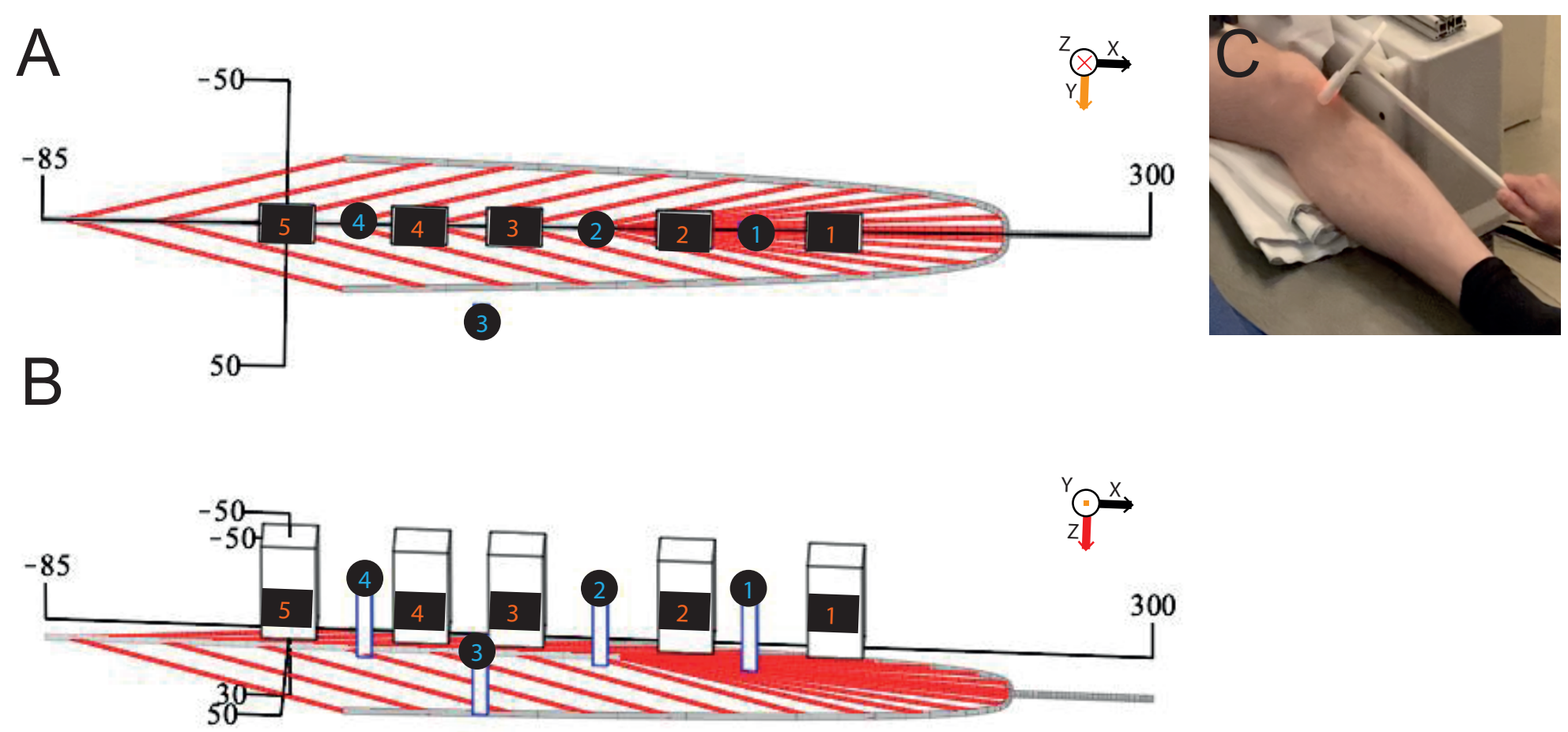

D

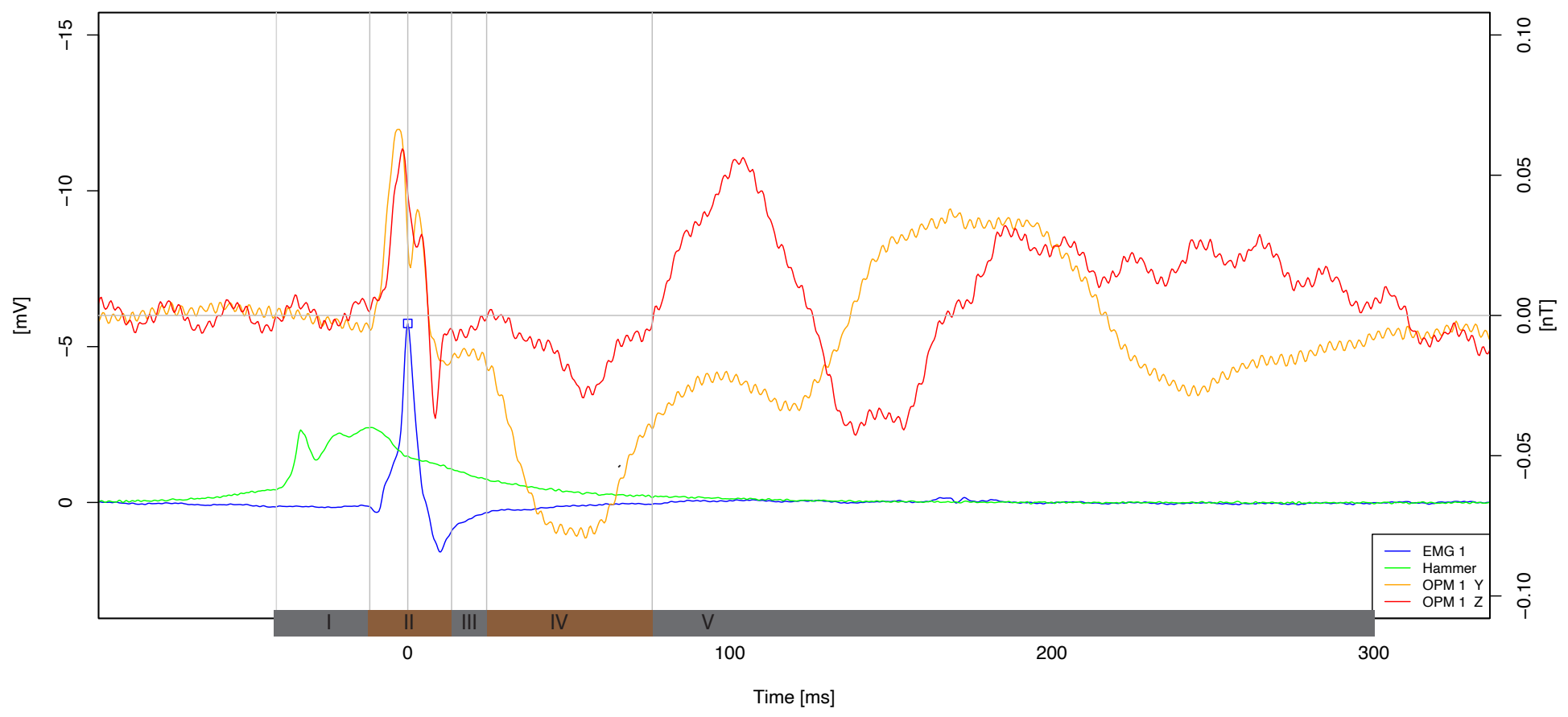


bioRxiv preprint doi: https://doi.org/10.1101/2021.02.24.432771; this version posted February 25, 2021. The copyright holder for this preprint (which was not certified by peer review) is the author/funder, who has granted bioRxiv a license to display the preprint in perpetuity. It is made available under aCC-BY-NC-ND 4.0 International license.

\section{Figure 03}

A
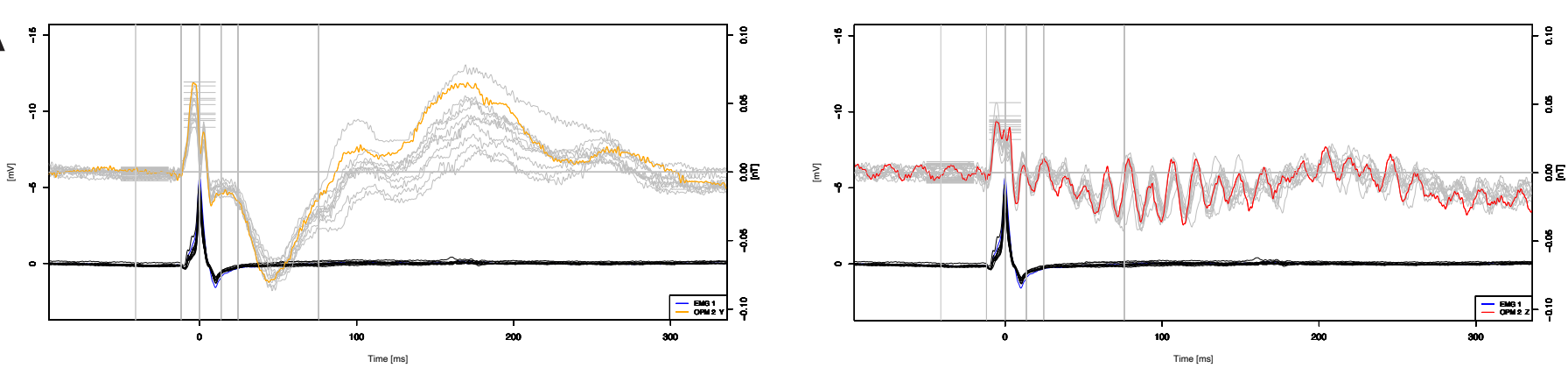

$\mathrm{B}$
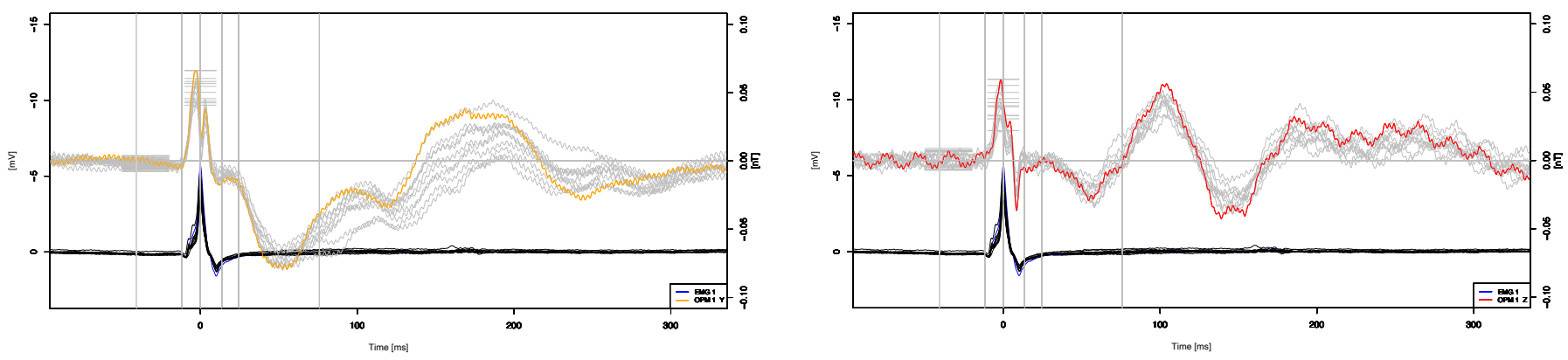

C
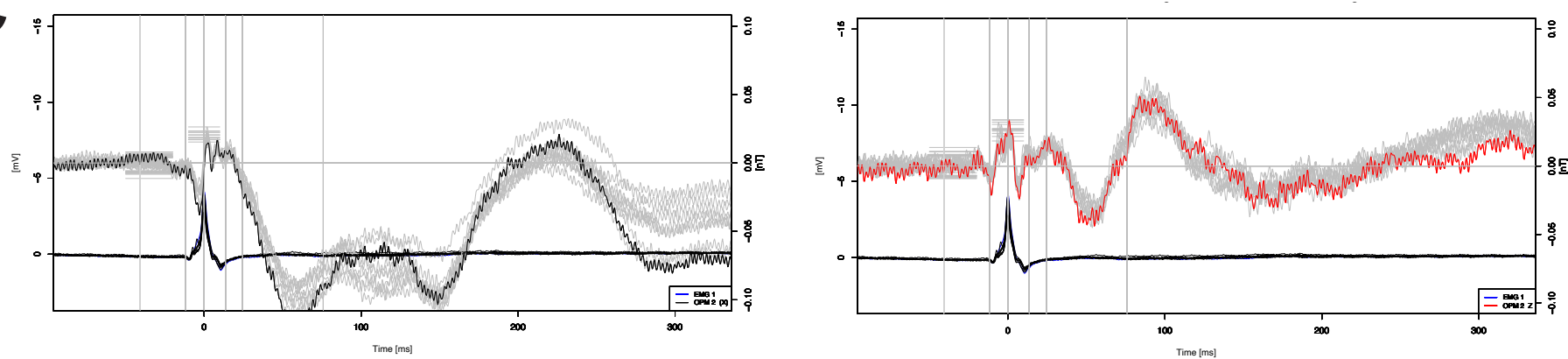

$\mathrm{D}$
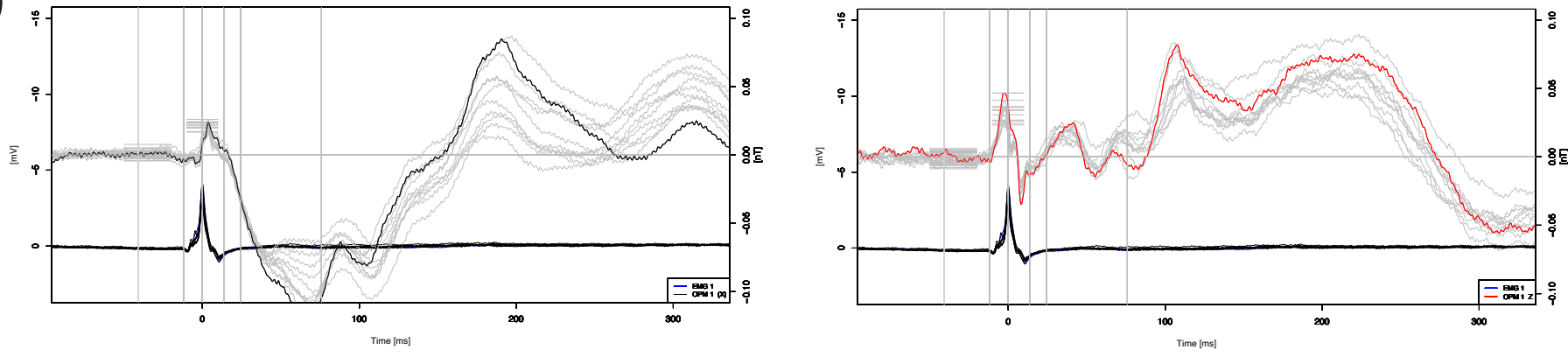
bioRxiv preprint doi: https://doi.org/10.1101/2021.02 24.432771; this version posted February 25, 2021. The copyright holder for this preprint (which was not certified by peer review) is the author/funder, who has granted bioRxiv a license to display the preprint in perpetuity. It is made available under aCC-BY-NC-ND 4.0 International license.

\section{Figure 04}

5

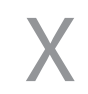

Y
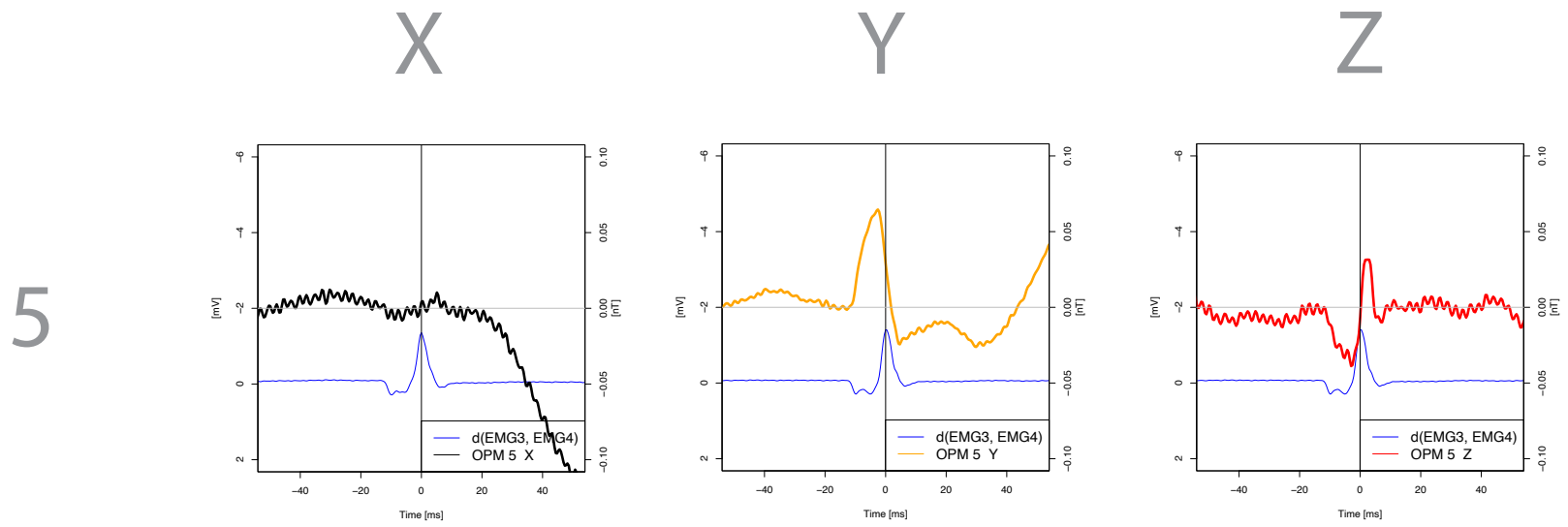

4
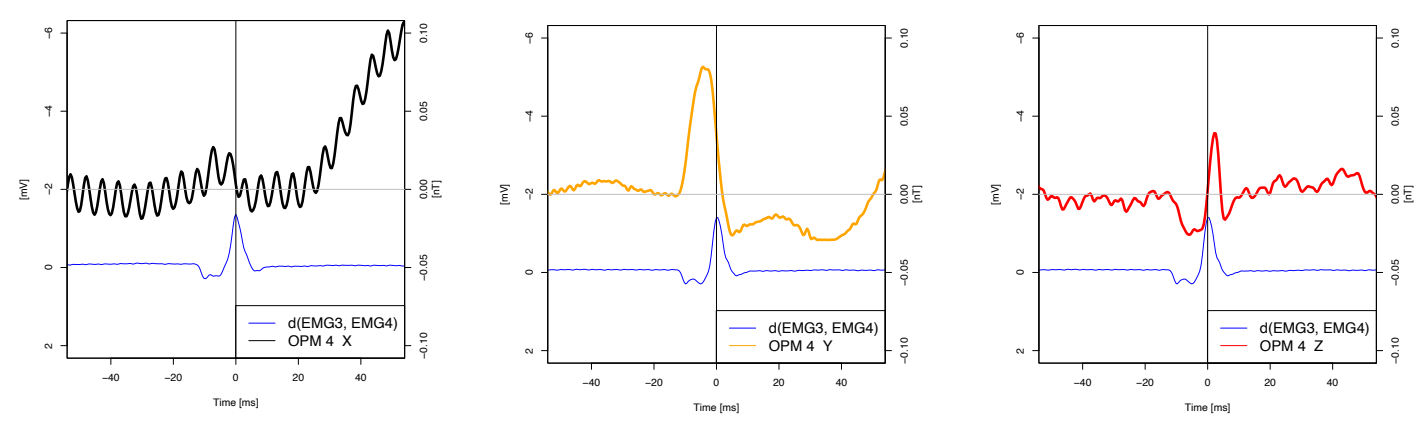

3
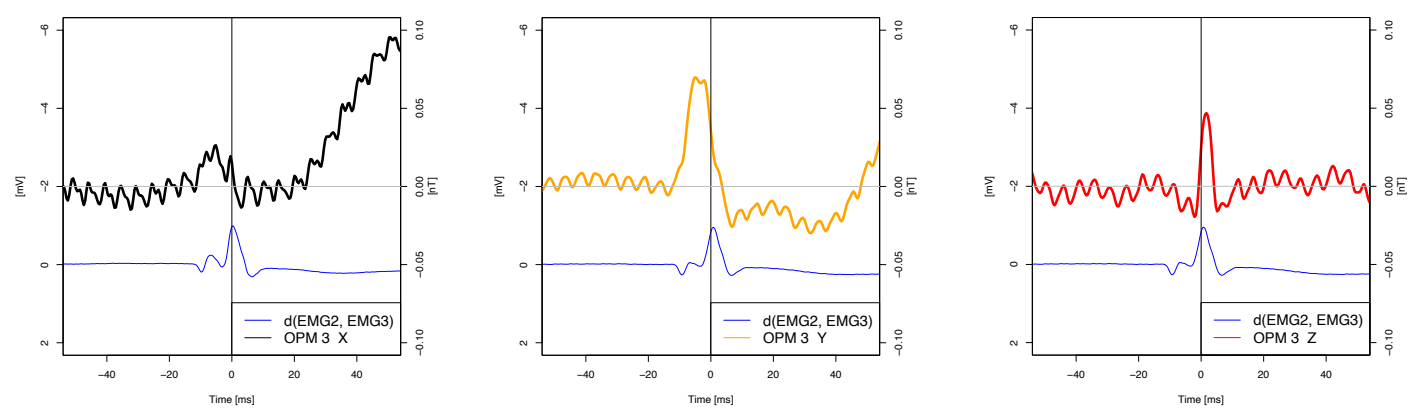

2
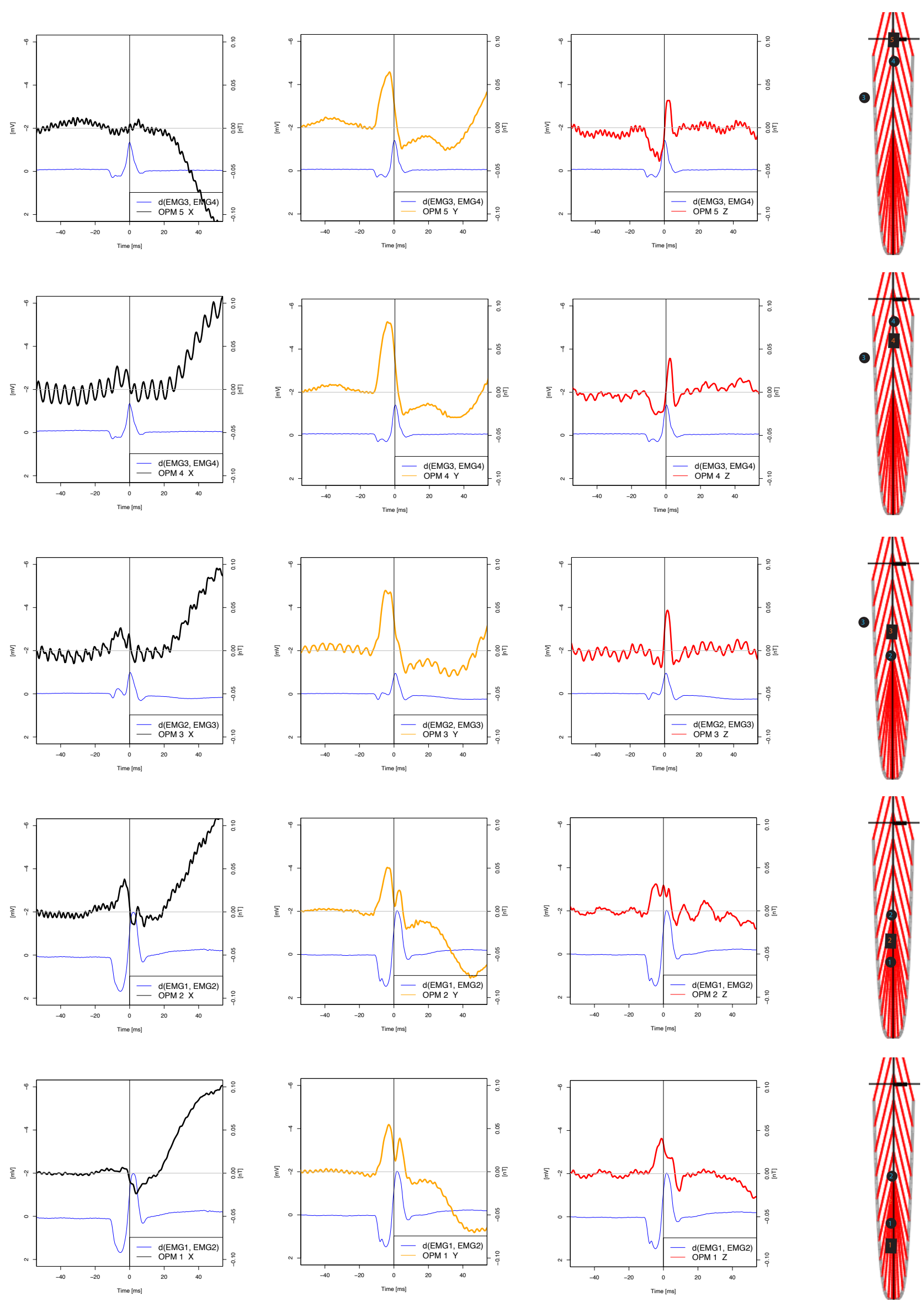
bioRxiv preprint doi: https://doi.org/10.1101/2021.02.24.432771; this version posted February 25, 2021. The copyright holder for this preprint (which was not certified by peer review) is the author/funder, who has granted bioRxiv a license to display the preprint in perpetuity. It is made available under aCC-BY-NC-ND 4.0 International license.

\section{Figure 05}
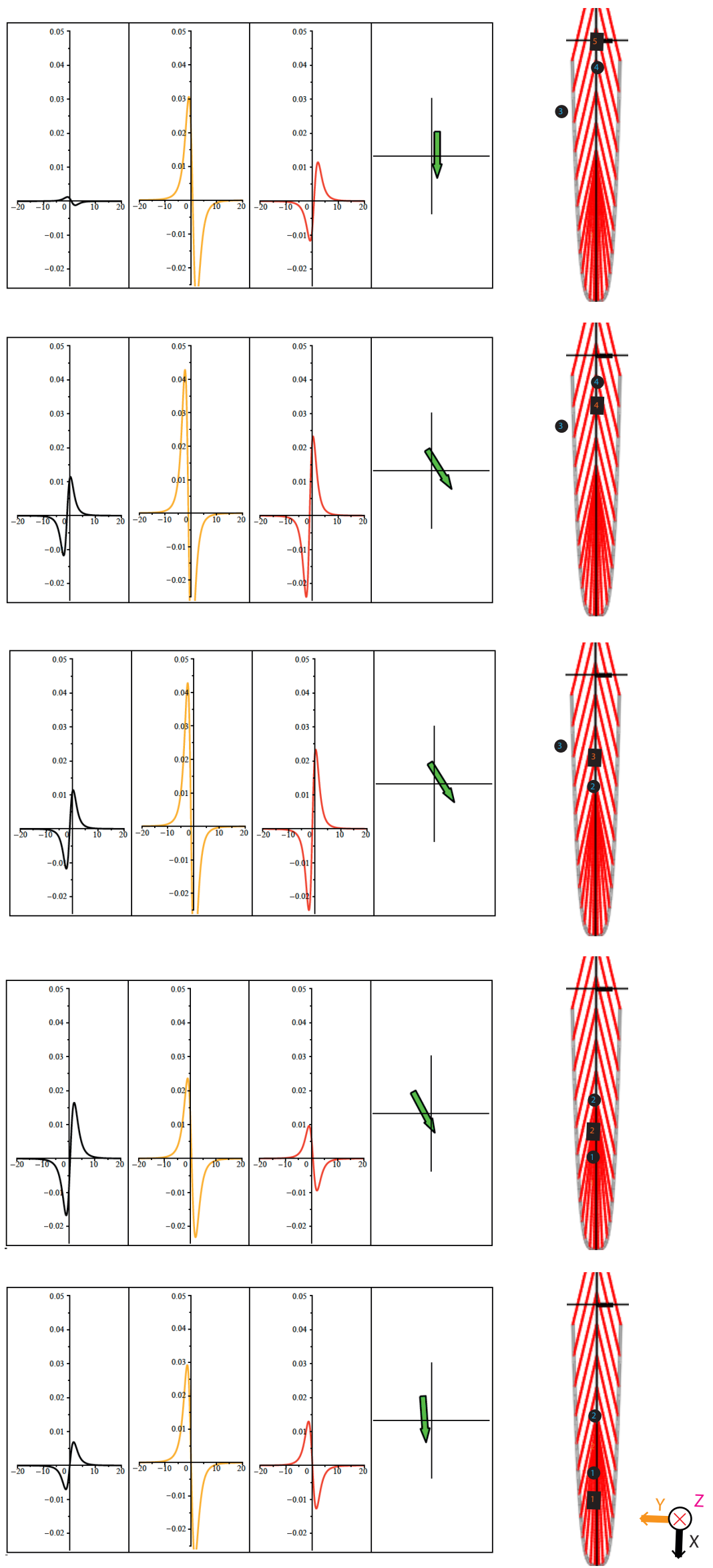
bioRxiv preprint doi: https://doi.org/10.1101/2021.02.24.432771; this version posted February 25, 2021. The copyright holder for this preprint (which was not certified by peer review) is the author/funder, who has granted bioRxiv a license to display the preprint in perpetuity. It is made available under aCC-BY-NC-ND 4.0 International license.

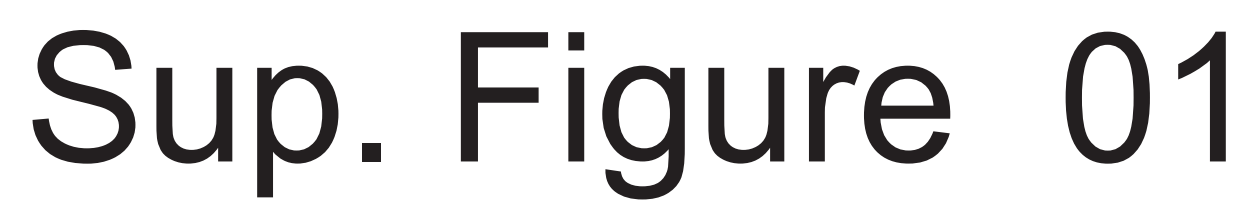

A

B
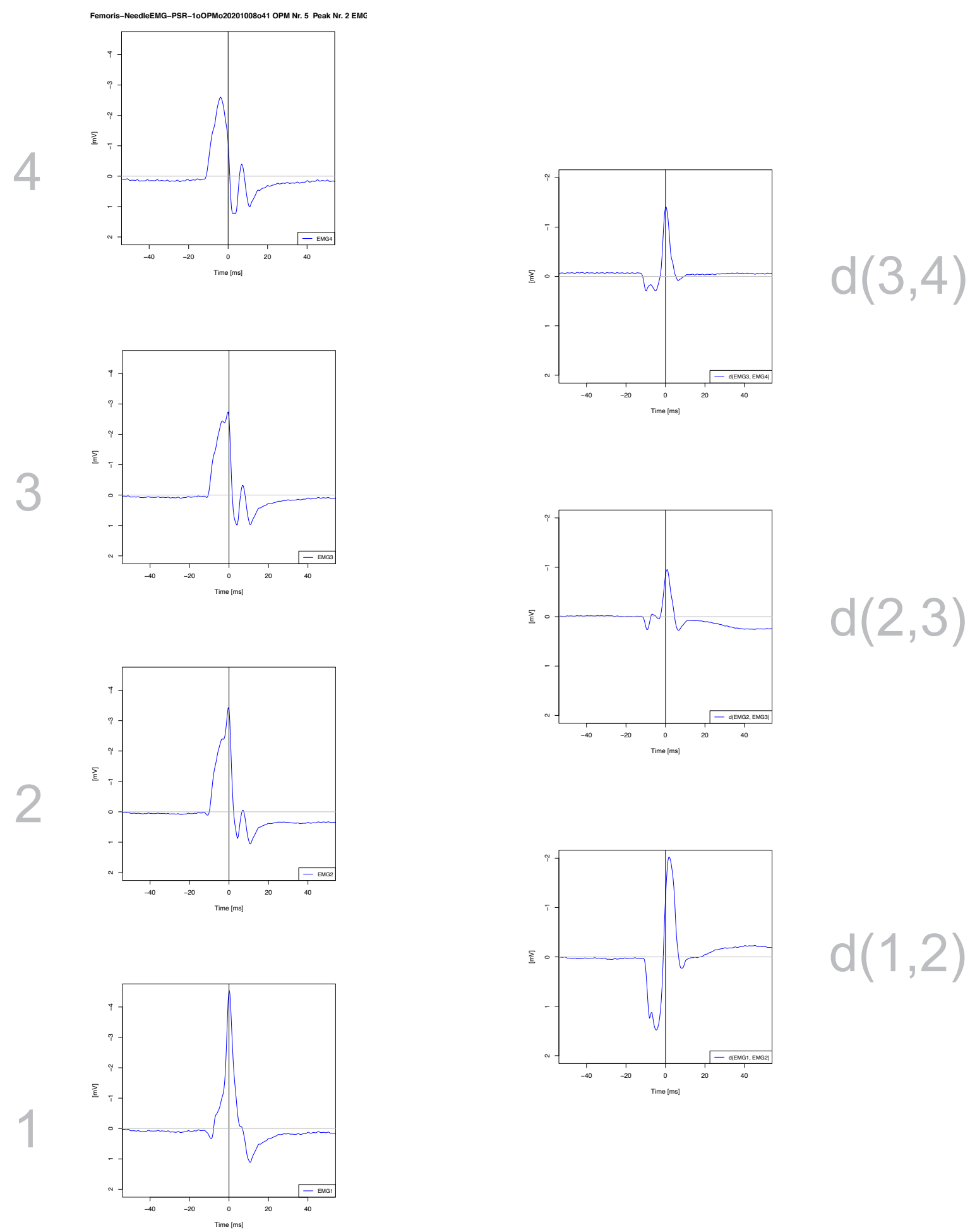


\section{Supplementary 02}
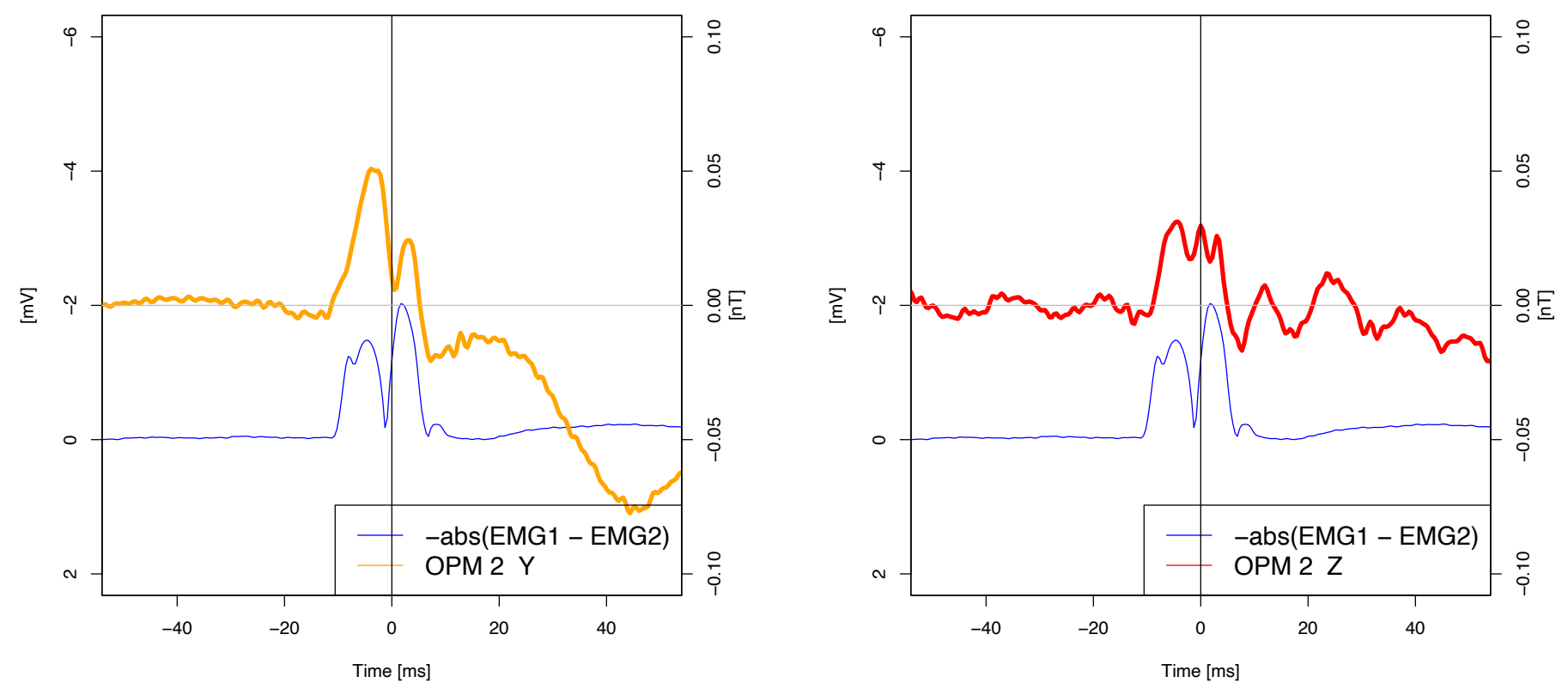